\title{
Storm damages and inter-city trade
}

\author{
In a world of increasingly integrated supply chains, disasters have impacts far from where they hit. A new paper \\ looks at how tropical-cyclone impacts propagate across cities, showing that indirect impacts become large for the \\ most-destructive storms.
}

\section{Stephane Hallegatte}

$\Lambda$ $s$ the consequences of COVID-19 become increasingly visible worldwide, it is clear that global supply chains are playing a key role in propagating and magnifying economic impacts. Yet this is not the first time supply chains have been disrupted by an external shock. In 2011, floods in Thailand and the Great Tōhoku earthquake in Japan resulted in economic impacts across the globe, especially in the electronics and automotive sectors ${ }^{1}$. Beyond anecdotal evidence, empirical studies confirm that supply chains play a crucial role in determining disaster costs ${ }^{2}$. After the 2011 earthquake in Japan, US affiliates of Japanese multinationals experienced a drop in output, which corresponded almost one-to-one to the drop of imports from Japan ${ }^{3}$. In practice, however, it is still common to measure the economic impact of a disaster based on local damages only.

The few studies looking at the spatial propagation of disasters' impacts are mostly based on input-output or computable general equilibrium models that represent the interaction across sectors in different regions ${ }^{4}$. More recently, new studies have focused on interactions at the firm level, but looking at within-country interactions mostly $^{5-7}$. Writing in Nature Sustainability, Shughrue and colleagues ${ }^{8}$ propose a new approach, using cities as the unit of analysis and focusing on industrial sectors. Such a focus makes sense considering the role of urban areas as the main hubs of the modern economic system and the fact that industrial supply chains are the most integrated globally and therefore the most vulnerable to global disruptions.

In their simulations, the authors quantify the negative secondary impacts of tropical cyclones, for instance the reduction in industrial production in non-affected cities due to lack of essential supplies or linked to a reduction in demand from affected cities. The secondary impacts occur only for very large disasters, but they can represent up to three times the value of direct impacts, confirming the importance of supply chains. Propagations through the economic system

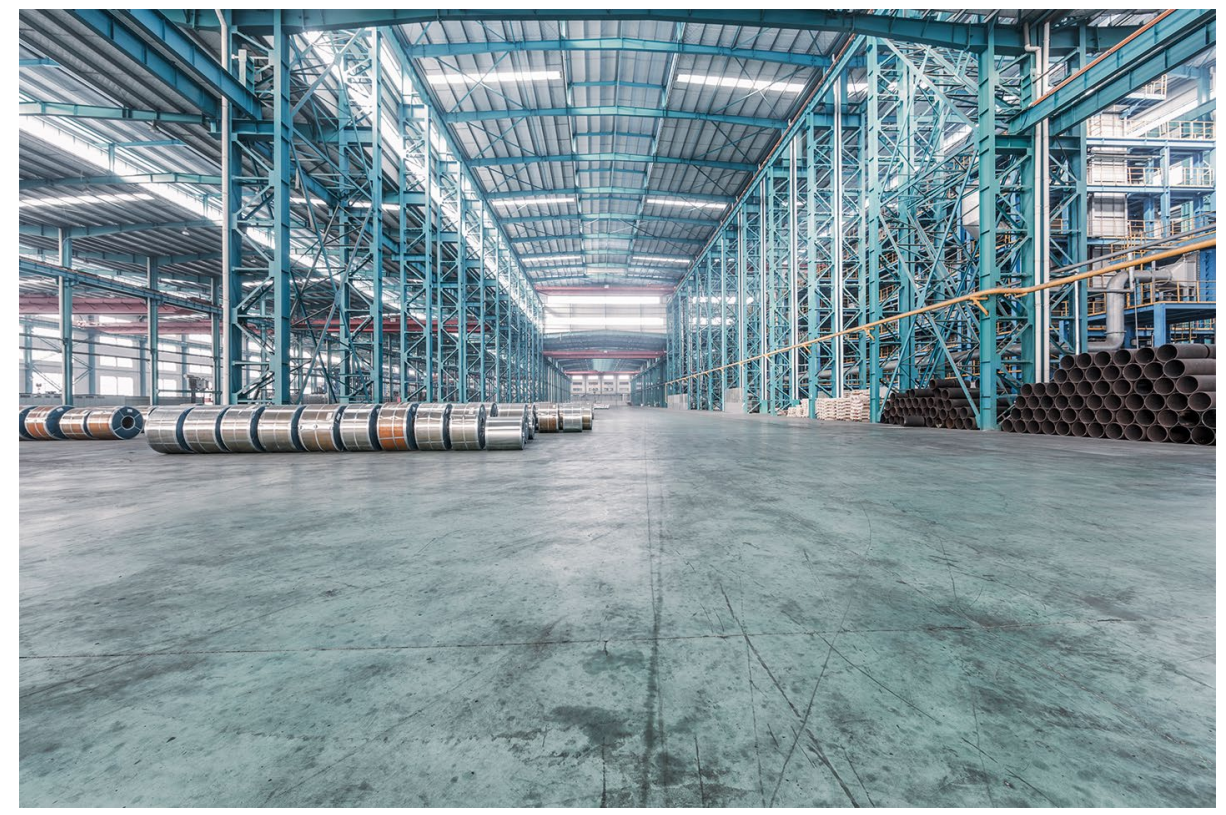

This mostly empty warehouse illustrates one repercussion of supply shocks, as from a cyclone or other natural disaster. Credit: chinaface / E+ / Getty.

are particularly important when producers of intermediate industrial goods are affected - this is the case in East Asia as illustrated by the 2011 floods in Thailand - or when major consumer centres are affected, as when large US cities are hit. Low-income cities that produce primary goods are not very dependent on global suppliers and are thus less vulnerable. Some cities may even become net beneficiaries if they are never affected directly and capture market share lost elsewhere. Interestingly, the results here closely mirror those from studies at the firm level, in which the vulnerability of firms depends on their position in supply chains $s^{2,7,9}$.

Shughrue et al. offer a timely contribution on disaster-impact propagation. First, they explore an interesting approach to spatial effects by using cities as the unit of analysis - in contrast to more-traditional national-, sectoral-, or firm-level analyses. And it adds to the few papers warning scholars investigating economic impacts of natural shocks and climate change against an excessive focus on local impacts; the vulnerability of one country, city or region cannot be determined by local physical impacts only but also depends on global interconnections. The study provides an important caveat to the empirical estimates of future climate-change impacts that predict losses in some countries and benefits in others ${ }^{10}$.

However, the paper also has important limitations, and its results remain more illustrative than definitive.

First, there are strong arguments to represent supply chains as interactions among firms instead of using more-aggregated approaches. Modelling exercises $^{5,6}$ and empirical work ${ }^{2,9}$ show that the nature of the supplier-client relationship matters for the ability of a firm to substitute one supplier (or client) for another. Here, the city-level approach can be defended based on the lack of more-granular data, but it 
would remain preferable to estimate a city's vulnerability using a firm-level analysis that is re-aggregated to the city level.

Second, more work remains to be done to explore the implications of various modelling assumptions and to better validate the model. For instance, impacts of Hurricane Sandy on supply chains were visible within the United States but undetectable in other countries ${ }^{9}$. How can we reconcile this result with the large secondary effects identified in this study? It may just be that Hurricane Sandy was not strong enough to trigger international repercussions, but a systematic comparison of models and empirical studies for a set of disasters of different magnitudes would be an important next step.

Third, the question remains of how global value chains and supply chains are being constructed and how they adjust to shocks. After shocks, firms react by diversifying or adjusting their network of suppliers, looking for new clients, or changing their management of inventories. In this paper, supply chains are assumed to be fixed, with adjustments limited to changes in the volume exchanged through existing supplier-client relationships. A priority for future research is to better understand how supply chains adjust to shocks to minimize losses, including how the transport infrastructure system can facilitate or impair such an adjustment ${ }^{7}$.

Finally, recent papers have considered global supply chains as a channel through which negative impacts can propagate. However, there is also evidence that better-connected firms are more resilient ${ }^{11}$ and that areas better connected to global markets tend to be less vulnerable to food insecurity. An important complement to existing work would be to apply a more-positive lens to this issue and explore how smart policies or investments can lead to more-nimble and flexible global supply chains that can help build resilience at the local, national and international levels.

\section{Stephane Hallegatte ${ }^{\bowtie}$}

Climate change group, The World Bank, Washington DC, USA.

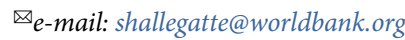

Published online: 4 May 2020

https://doi.org/10.1038/s41893-020-0524-7

References

1. Haraguchi, M. \& Lall, U. Int. J. Disaster Risk Reduct. 14, 256-272 (2015).

2. Barrot, J.-N. \& Sauvagnat, J. Q. J. Econ. 131, 1543-1592 (2016).

3. Boehm, C. E., Flaaen, A. \& Pandalai-Nayar, N. Rev. Econ. Stat. 101, 60-75 (2019).

4. Okuyama, Y. \& Rose, A. in Advances in Spatial and Economic Modeling of Disaster Impacts: Advances in Spatial Science (The Regional Science Series) (eds Okuyama, Y. \& Rose, A.) 1-11 (Springer International Publishing, 2019); https://go.nature. com/3bItJqw

5. Henriet, F., Hallegatte, S. \& Tabourier, L. J. Econ. Dyn. Control 36, 150-167 (2012).

6. Inoue, H. \& Todo, Y. Nat. Sustain. 2, 841-847 (2019).

7. Colon, C., Hallegatte, S. \& Rozenberg, J. Transportation and Supply Chain Resilience in the United Republic of Tanzania Assessing the Supply-Chain Impacts of Disaster-Induced Transportation disruptions World Bank background paper to the Lifelines Report (World Bank, 2019).

8. Shughrue, C., Werner, B. T. \& Seto, K. C. Nat. Sustain https://doi.org/10.1038/s41893-020-0523-8 (2020).

9. Kashiwagi, Y., Todo, Y. \& Matous, P. International Propagation of Economic Shocks through Global Supply Chains WINPEC Working Paper E1810 (WINPEC, Waseda Univ., 2018)

10. Burke, M., Hsiang, S. M. \& Miguel, E. Nature 527, 235-239 (2015).

11. Kashiwagi, Y. \& Todo, Y. Propagation of Positive Effects of Post-Disaster Policies Through Supply Chains: Evidence from the Great East Japan Earthquake RIETI Discussion Paper Series 19-E-030 (RIETI, 2019). 